Case Report

\title{
An Interval Fuzzy, Double-Sided, Chance- Constrained Stochastic Programming Model for Planning the Ecological Service Value of Interconnected River Systems
}

\author{
Luze Yang ${ }^{1, *}$, Weiyi Cong ${ }^{2}$, Chong Meng ${ }^{3}$, Baofeng Cai ${ }^{4}$ and Miao Liu ${ }^{1, *}$ \\ College of New Energy and Environment, Jilin University, Changchun 130012, China \\ Environmental Science Research Institute of Jilin, Changchun 130012, China; weiyi899630@163.com \\ 3 State Key Laboratory of Water Environment Simulation, School of Environment, Beijing Normal University, \\ Beijing 100875, China; meng@bnu.edu.cn \\ 4 Department of Ecology and Environment of Jilin, Changchun 130012, China; cbf777@sohu.com \\ * Correspondence: yanglz19@mails.jlu.edu.cn (L.Y.); liumiao@jlu.edu.cn (M.L.)
}

Received: 3 August 2020; Accepted: 17 September 2020; Published: 22 September 2020

check for updates

\begin{abstract}
The western region of Jilin Province is an ecologically fragile area with scarce water resources. The effective allocation of the limited water resources in order to obtain a higher ecological service value is an urgent requirement. In this paper, an interval fuzzy, double-sided chance-constrained, stochastic programming (IFDCP) model was used based on the interconnected river system network project in the western Jilin Province. With the objective of maximizing the value of regional ecological services, the water diversion and supplement schemes were optimized and adjusted. The model results showed that the restored water surface area of all lakes and ponds in the western region of Jilin Province was higher than the initially planned scheme in the high flow year. The water surface area fulfilled the minimum constraints, but did not fulfill the initial scheme in the normal flow year. In the low flow year, the lower limit of some of the regions had to be decreased in order to meet the allocation of the limited water resources. The proportion of floodwater resource utilization gradually increased with an increase in the flood amount. The ecological service value produced in the normal and high flow years was found to be higher than the initial scheme. The marsh wetland can produce higher ecological service value. Therefore, the core of the model optimization was introducing more water to the marsh wetland after fulfilling the basic consumption of ponds and the reed wetland. In addition, the IFDCP model was more flexible in water diversion and supplement as compared to other models that had been developed previously.
\end{abstract}

Keywords: interval fuzzy; double-sided; chance-constrained stochastic programming; ecological services; water diversion and supplement

\section{Introduction}

The western Jilin Province is located in the Songnen Plain, and it is an ecologically fragile area with little rainfall, serious soil salinization, and a sensitive ecological environment [1]. The interconnected river system network project can improve the self-healing ability of the water body by enhancing fluidity and continuity, and can realize the long-term health and stability of the water body [2]. Water ecological services are primarily the ecological value and the economic value of water resources [3], which are the benefits that organisms directly or indirectly obtain from ecosystems [4]. The wetland ecosystem is one of the most significant ecosystems on Earth [5]. Only covering $6 \%$ of the total terrestrial ecosystem area, wetlands can produce about $45 \%$ of the ecological service value of the total terrestrial ecosystem 
on the Earth [6,7]. Due to the high ecological service value of wetlands, their water supply should be allocated reasonably. According to Zhang et al.'s study, the total wetland area decreased sharply and the patch density increased significantly from 1950s to 2012, indicating that it is very important to rationally use water resources to replenish wetlands [8]. Zhang et al. studied the water supply requirement of wetlands in western Jilin Province, which did not comprehensively consider the water requirement of lake and ponds and the water allocation for the optimal value of ecological service [1]. Therefore, it is very important to study the rational allocation of water resources to maximize the ecological service value in the interconnected river systems in the western Jilin Province.

Previously, Cai et al. optimized the ecological service value of the western Jilin Province by using double-sided, chance-constrained stochastic programming [9]; fuzzy, double-sided, chance-constrained programming [10]; and fuzzy two-stage, chance-constrained stochastic programming methods [11]; among these, the two-stage programming model may cause instability and system risk in the model, due to the difference and uncertainty of the second-stage penalty. At the same time, the above methods did not fully consider the volatility of all parameters. Fuzzy mathematical programming offers a powerful method of handling optimization problems with non-stochastic imprecision and vagueness [12]. The chance-constrained programming (CCP) model is the most typical stochastic mathematical programming (SMP) method to present and deal with uncertainty expressed as random information, which can easily be integrated with other optimization approaches in order to deal with multiform uncertainties [9]. Interval linear programming and deterministic values of parameters and results are considered in the form of interval numbers in uncertain systems. The three methods can be used together to solve the problems of interval volatility, fuzzy uncertainty, and the randomness of parameters. Previously, researchers used the interval fuzzy, double-sided, chance-constrained stochastic programming (IFDCP) model in order to optimize the land-use allocation of Guizhou, the irrigation water allocation of Heihe, and the water resource management of Fenhe, respectively [13-15]; however, the IFDCP has not been applied to water allocation based on an interconnected river system before. The IFDCP has the advantages of enhancing a system's robustness and handling fuzzy sets on both sides of the constraints [15]. In conclusion, the IFDCP considers the volatility, randomness, and ambiguity of the model parameters. Therefore, in this paper, the IFDCP was used to develop an optimization model of the ecological services for the western Jilin Province, which provided more decision-making schemes for the water diversion and supply.

It is particularly important to obtain the maximum ecological service value by effectively using and allocating the limited water resources, because the western Jilin Province is relatively short of water. This paper aimed to maximize the ecological service value of the interconnected river system network project in the western Jilin Province. The volatility of parameters, the randomness of flood resources and ecological water demand, and the fuzziness of the water surface and wetland area were completely considered. The IFDCP was used to optimize the regional water diversion and supplement scheme of the interconnected river system network project in the western Jilin Province in the three water scenarios (low flow year, normal flow year, and high flow year), providing a feasible plan for further improving the ecological service value. It demonstrates positive significance for the study of water diversion and supplement and ecological service value optimization.

\section{Case Study}

The study area includes the western Jilin Province, including Songhua River, Nenjiang River, Taoer River, and Huolin River, as well as 15 counties and districts. The total area is $4.46 \times 10^{4} \mathrm{~km}^{2}$. There are four national nature reserves: Xianghai, Momoge, Chagan Lake, and Boluo Lake. The Xianghai Nature Reserve primarily aims at protecting rare waterfowl, such as the red-crowned crane, and rare plant communities, such as the Mongolian yellow elm. The Momoge Nature Reserve is the largest wetland reserve in Jilin Province, known as the kidney of the western Jilin Province. The Chagan Lake is the largest natural lake in Jilin Province. The sketch map of western Jilin Province is shown in Figure 1. 


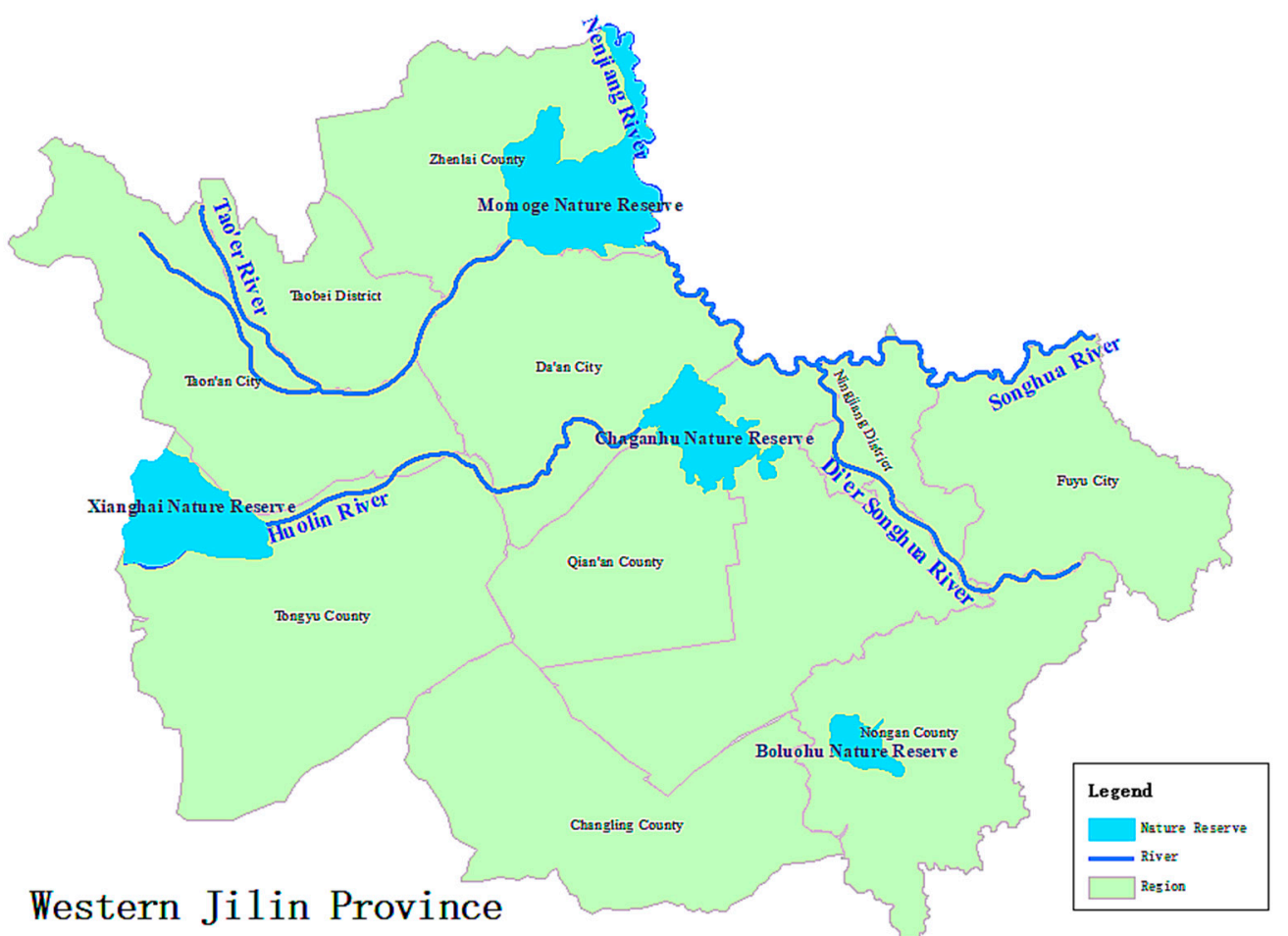

Figure 1. The sketch map of western Jilin Province.

\section{Model Formulation}

\subsection{Ecological Service Value Optimization Model, Based on the Interval, Double-Sided, Chance-Constrained Stochastic Programming Model}

This paper aims to maximize the ecological service value by optimizing the utilization and distribution of water resources of the interconnected river system network project in the western Jilin Province. The amount of flood resources and the ecological water demand are random, with the influence of rainfall, climate, etc. The chance-constrained stochastic programming method was adopted, and the randomness of flood resources was completely followed. Besides, all parameters were considered uncertain, with the characteristics of up-and-down fluctuations in the process of contributing to the ecological service value. The parameter values were set within a reasonable interval after comprehensively considering the uncertainty of all parameters. Then, the interval linear programming method was introduced. The diversion and supplement plan of water resources was obtained by using interval, double-sided, chance-constrained stochastic programming (IDCP), and the objective function is determined as follows:

$$
\max f^{ \pm}=\sum_{i=1}^{198} \sum_{j=1}^{4} \sum_{k=1}^{15} E B W_{i j k}^{ \pm} \cdot F A_{i j}^{ \pm}
$$

where $f^{ \pm}$represents the interval value of ecological service value of the region of the interconnected river system network project, $i$ represents the 198 lakes and ponds of the western Jilin Province, $j$ represents different types of functions of the lakes and ponds $(j=1,2,3$, and 4 represents the fish pond, crab pond, reed wetland, and marsh wetland, respectively), $k$ represents different types of ecological services, $E B W_{i j k}^{ \pm}$represents the interval value of the ecological service value of the ecological service $k$ of the function $j$ in the lake and pond $i\left(10^{6} \mathrm{CNY} / 10^{4}\right.$ ha), and $F A_{i j}^{ \pm}$represents the interval value of the supplement area of the function $j$ in the lake and pond $i\left(10^{4} \mathrm{ha}\right)$. 
The implementation of the IFDCP model needs to be limited by area, water amount, and so on, so constraints need to be set to ensure the rationality of the optimization results. This paper is based on existing studies, and retained the previous constraints for further comparison and analysis. The constraints include the total water amount, the water amount of lake and pond, and the area of lake and pond. Besides, the water diversion and supplement have priority; for example, the water requirements for fish and crab ponds and reed wetland should be met first. The constraints are as follows:

(1) Constraints for water diversion and supplementation order:

$$
\begin{gathered}
\sum_{m=1}^{3} Q_{i m}^{ \pm}-Q L_{i m}^{ \pm}-Q W_{i}^{ \pm} \geq A P_{i}^{ \pm} \cdot Q W R_{i}^{ \pm}, \forall i \\
A P_{i}^{ \pm} \geq A P_{\min i}^{ \pm}, \forall i \\
F A_{i 4}^{ \pm} \cdot Q P_{i 4}^{ \pm}=\left\{\begin{array}{l}
Q W_{i}^{ \pm}-F A_{i 3}^{ \pm} \cdot Q P_{i 3}^{ \pm}, \text {if } F A_{i 3}^{ \pm} \geq F A_{\text {mini3 }}^{ \pm}, \forall i \\
0, \text { if } F A_{i 3}^{ \pm} \leq F A_{\text {mini3 }}^{ \pm}
\end{array},\right.
\end{gathered}
$$

where $m$ represents the source of the diversion and supplement of water $(m=1,2$, and 3 represents the local water resources, normal supplement, and flood resources, respectively), $Q_{i m}^{ \pm}$is the interval value of the incoming water amount of water source $m\left(10^{4} \mathrm{~m}^{3}\right), Q L_{i m}^{ \pm}$is the interval value of the water loss of the water source $m$ of the lake and pond $i\left(10^{4} \mathrm{~m}^{3}\right), Q W_{i}^{ \pm}$is the interval value of the wetland water consumption of the lake and pond $i\left(10^{4} \mathrm{~m}^{3}\right), A P_{i}^{ \pm}$is the interval value of the water surface area of the lake and pond $i\left(10^{4} \mathrm{ha}\right), Q W R_{i}^{ \pm}$is the interval value of the unit water demand quota of the lake and pond $i\left(10^{4} \mathrm{~m}^{3} / 10^{4} \mathrm{ha}\right), A P_{\min i}^{ \pm}$is the interval value of the minimum water surface area of the lake and pond $i\left(10^{4} \mathrm{ha}\right), Q P_{i j}^{ \pm}$is the interval value of the unit water demand quota of the function $j$ of the lake and pond $i\left(10^{4} \mathrm{~m}^{3} / 10^{4} \mathrm{ha}\right)$, and $F A_{\text {mini3 }}^{ \pm}$is the interval value of the minimum supplement area of the reed wetland in the lake and pond $i\left(10^{4} \mathrm{ha}\right)$;

(2) Constraints for functional area:

$$
\begin{aligned}
& \sum_{j=1}^{2} F A_{i j}^{ \pm} \leq A P_{i}^{ \pm}, \forall i \\
& F A_{i j}^{ \pm} \leq F A_{\text {max } i j}^{ \pm}, \forall i, j
\end{aligned}
$$

where $F A_{\text {max } i j}^{ \pm}$is the interval value of the maximum supplement area of the reed wetland in the lake and pond $\left(10^{4} \mathrm{ha}\right)$;

(3) Constraints for the diversion and supplement of water amount:

$$
\sum_{j=1}^{4} F A_{i j}^{ \pm} \cdot Q P_{i j}^{ \pm} \leq \sum_{m=1}^{3} Q_{i m}^{ \pm}-Q L_{i m^{\prime}}^{ \pm}, \forall i
$$

(4) Constraints for the total water amount:

$$
\operatorname{Pr}\left\{\begin{array}{l}
\sum_{i=1}^{I_{r}}\left[\sum_{j=1}^{3} F A_{i j}^{ \pm} \cdot Q P_{i j}^{ \pm}+F A_{i 4}^{ \pm} \cdot Q P_{i 4}^{ \pm}(\omega)\right] \\
\leq Q T_{r}^{ \pm}+R F_{r}^{ \pm}(\omega)
\end{array}\right\} \geq 1-\theta_{r}^{ \pm}, \forall r
$$

where $r$ represents 15 administrative regions for project water diversion and supplement, $Q T_{r}^{ \pm}$is the interval value of the effective flood resources in the area $r\left(10^{4} \mathrm{~m}^{3}\right), R F_{r}{ }^{ \pm}$is the interval value of 
precipitation in the area $r\left(10^{4} \mathrm{~m}^{3}\right), \theta_{r}^{ \pm}$is the interval value of the probability of violating the constraint, and $\omega$ represents the randomness of relevant parameters.

\subsection{Ecological Service Value Optimization Model Based on the Interval Fuzzy, Double-Sided, Chance-Constrained Stochastic Programming}

The area of water surface and wetland has fuzzy uncertainty, and the fuzzy method was introduced to optimize the programming, in order to achieve the maximum value of the ecological service value. The minimum values of the water surface area, functional area, and total area were set as fuzzy variables. The diversion and supplement plan of water resources was obtained by using the IFDCP, and the objective function is calculated as follows:

$$
\max \lambda^{ \pm}
$$

where $\lambda^{ \pm}$is the interval value of the fuzzy membership.

The constraints are

$$
\sum_{i=1}^{198} \sum_{j=1}^{4} \sum_{k=1}^{15} E B W_{i j k}^{ \pm} \cdot F A_{i j}^{ \pm} \geq f^{+}-\left(1-\lambda^{ \pm}\right)\left(f^{+}-f^{-}\right)
$$

where $f^{+}$and $f^{-}$are the upper and lower bounds obtained from the IDCP. The IFDCP model also include the following:

(1) Constraints for water diversion and supplementation order:

$$
\begin{gathered}
\sum_{m=1}^{3} Q_{i m}^{ \pm}-Q L_{i m}^{ \pm}-Q W_{i}^{ \pm} \geq A P_{i}^{ \pm} \cdot Q W R_{i}^{ \pm}, \forall i \\
A P_{i}^{ \pm} \geq A P_{i \min }^{+}-\left(1-\lambda^{ \pm}\right) \cdot\left(A P_{i \text { min }}^{+}-A P_{i \min }^{-}\right), \forall i \\
F A_{i 4}^{ \pm} \cdot Q P_{i 4}^{ \pm}=\left\{\begin{array}{l}
Q W_{i}^{ \pm}-F A_{i 3}^{ \pm} \cdot Q P_{i 3}^{ \pm}, \text {if } F A_{i 3}^{ \pm} \geq F A_{\text {mini3 }}^{ \pm}, \forall i \\
0, \text { if } F A_{i 3}^{ \pm} \leq F A_{\text {mini } 3}^{ \pm}
\end{array},\right.
\end{gathered}
$$

(2) Constraints for the functional area:

$$
\begin{gathered}
\sum_{j=1}^{2} F A_{i j}^{ \pm} \leq A P_{i}^{ \pm}, \forall i \\
A P_{i}^{ \pm} \leq A P_{i \max }^{-}+\left(1-\lambda^{ \pm}\right)\left(A P_{i \max }^{+}-A P_{i \max }^{-}\right), \forall i \\
F A_{i j}^{ \pm} \leq F A_{i j \max }^{-}+\left(1-\lambda^{ \pm}\right) \cdot\left(F A_{i j \max }^{+}-F A_{i j \max }^{-}\right), \forall i, j \\
\sum_{j=1}^{4} F A_{i j}^{ \pm} \leq P L A_{i}^{-}+\left(1-\lambda^{ \pm}\right)\left(P L A_{i}^{+}-P L A_{i}^{-}\right), \forall i
\end{gathered}
$$

(3) Constraints for the diversion and supplement of water amount:

$$
\sum_{j=1}^{4} F A_{i j}^{ \pm} \cdot Q P_{i j}^{ \pm} \leq \sum_{m=1}^{3} Q_{i m}^{ \pm}-Q L_{i m^{\prime}}^{ \pm}, \forall i
$$

(4) Constraints for the total water amount: 


$$
\operatorname{Pr}\left\{\begin{array}{l}
\sum_{i=1}^{I_{r}}\left[\sum_{j=1}^{3} F A_{i j}^{ \pm} \cdot Q P_{i j}^{ \pm}+F A_{i 4}^{ \pm} \cdot Q P_{i 4}^{ \pm}(\omega)\right] \\
\leq Q T_{r}^{ \pm}+R F_{r}^{ \pm}(\omega)
\end{array}\right\} \geq 1-\theta_{r}^{ \pm}, \forall r
$$

\subsection{Model Parameters}

The parameters for establishing the IFDCP model were adopted from previous studies [2,15], and the original parameters were reasonably adjusted to be interval parameters within a certain range. The Lingo software was used to solve the model. First, the IDCP model was solved, and the optimization scheme for the water diversion and supplement of the low flow year, normal flow year, and high flow year was obtained. Then, the fuzzy programming was applied to further optimize the interval results. Finally, the optimization scheme of the IFDCP was obtained. The flow chart of IFDCP model is shown in Figure 2.

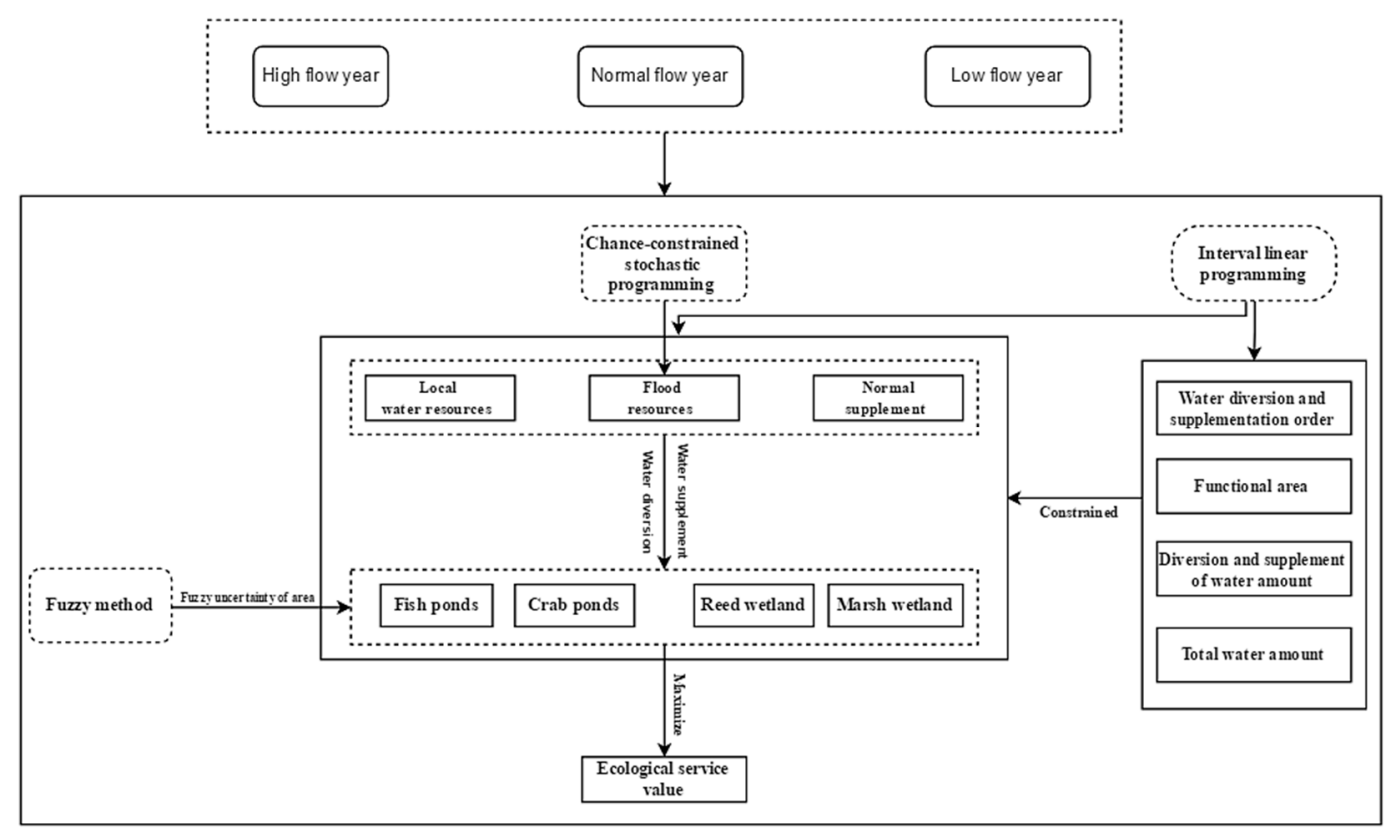

Figure 2. The flow chart of interval fuzzy, double-sided, chance-constrained stochastic programming (IFDCP) model.

\section{Results}

\subsection{Results of the Restored Area of Wetlands, Lakes, and Ponds Based on the IFDCP}

The system was divided into three scenarios (low flow year, normal flow year, and high flow year) according to the differences in the flood water amount at different times of the western Jilin. The three scenarios were optimized for the ecological services based on the IFDCP. In the three scenarios, the interval fuzzy memberships were 0.007-1.000, 0.030-0.960, and 0.090-0.870, respectively. The restored water surface area (fishpond area and crab pond area) and wetland area (reed wetland and marsh wetland) in the three scenarios are shown in Tables 1 and 2 and Figure 3. 
Table 1. Interval value of the restored fishpond area and the crab pond area.

\begin{tabular}{|c|c|c|c|c|c|c|c|c|}
\hline \multirow[b]{2}{*}{ Region } & \multicolumn{4}{|c|}{$\begin{array}{l}\text { Fishpond Area } \\
\left(10^{4} \mathrm{ha}\right)\end{array}$} & \multicolumn{4}{|c|}{$\begin{array}{l}\text { Crab Pond Area } \\
\left(10^{4} \mathrm{ha}\right)\end{array}$} \\
\hline & $\begin{array}{c}\text { Initial } \\
\text { Planned } \\
\text { Scheme }\end{array}$ & $\begin{array}{l}\text { Low } \\
\text { Flow } \\
\text { Year }\end{array}$ & $\begin{array}{c}\text { Normal } \\
\text { Flow } \\
\text { Year }\end{array}$ & $\begin{array}{l}\text { High } \\
\text { Flow } \\
\text { Year }\end{array}$ & $\begin{array}{c}\text { Initial } \\
\text { Planned } \\
\text { Scheme }\end{array}$ & $\begin{array}{l}\text { Low } \\
\text { Flow } \\
\text { Year }\end{array}$ & $\begin{array}{c}\text { Normal } \\
\text { Flow } \\
\text { Year }\end{array}$ & $\begin{array}{l}\text { High } \\
\text { Flow } \\
\text { Year }\end{array}$ \\
\hline 1 & 0.75 & $0.75-0.75$ & $0.76-0.78$ & $0.8-0.93$ & 0.28 & $0.28-0.37$ & $0.29-0.37$ & $0.38-0.37$ \\
\hline 2 & 3.45 & $3.2-3.47$ & $3.43-3.47$ & $3.44-3.72$ & 0.02 & $0.02-0.02$ & $0.02-0.03$ & $0.03-0.03$ \\
\hline 3 & 0.17 & $0.17-0.17$ & $0.24-0.22$ & $0.24-0.23$ & 0.18 & $0.18-0.18$ & $0.25-0.24$ & $0.25-0.24$ \\
\hline 4 & 0.15 & $0.09-0.11$ & $0.15-0.16$ & $0.18-0.19$ & 0 & $0-0$ & $0-0$ & $0-0$ \\
\hline 5 & 0 & $0-0$ & $0-0$ & $0-0$ & 0 & $0-0$ & $0-0$ & $0-0$ \\
\hline 6 & 0 & $0-0$ & $0-0$ & $0-0$ & 0 & $0-0$ & $0-0$ & $0-0$ \\
\hline 7 & 0.03 & $0.03-0.03$ & $0.03-0.03$ & $0.03-0.03$ & 0.01 & $0.01-0.01$ & $0.01-0.01$ & $0.01-0.01$ \\
\hline 8 & 0.84 & $0.42-0.53$ & $0.83-0.84$ & $1.02-1.09$ & 0.14 & $0.07-0.09$ & $0.13-0.17$ & $0.18-0.18$ \\
\hline 9 & 0.91 & $0.21-0.9$ & $0.9-0.91$ & $1.01-1.11$ & 0.02 & $0.02-0.02$ & $0.02-0.02$ & $0.03-0.03$ \\
\hline 10 & 1.19 & $0.45-0.93$ & $1.19-1.2$ & $1.34-1.42$ & 0.02 & $0.02-0.02$ & $0.02-0.02$ & $0.03-0.03$ \\
\hline 11 & 0 & $0-0$ & $0-0$ & $0-0$ & 0 & $0-0$ & $0-0$ & $0-0$ \\
\hline 12 & 0.36 & $0-0.36$ & $0.36-0.36$ & $0.36-0.36$ & 1.27 & $1.21-1.25$ & $1.26-1.27$ & $1.26-1.32$ \\
\hline 13 & 0 & $0-0$ & $0-0$ & $0-0$ & 0.06 & $0.06-0.06$ & $0.06-0.06$ & $0.06-0.07$ \\
\hline 14 & 0.14 & $0-0.14$ & $0.14-0.14$ & $0.14-0.14$ & 0.36 & $0.32-0.37$ & $0.36-0.36$ & $0.38-0.44$ \\
\hline 15 & 0.15 & $0-0.13$ & $0.15-0.15$ & $0.17-0.18$ & 0.02 & $0.01-0.01$ & $0.02-0.02$ & $0.02-0.02$ \\
\hline Total & 8.15 & $5.3-7.53$ & $8.19-8.26$ & $8.71-9.39$ & 2.38 & $2.2-2.41$ & $2.44-2.56$ & $2.64-2.73$ \\
\hline
\end{tabular}

Table 2. Interval value of the reed wetland area and the marsh wetland area.

\begin{tabular}{|c|c|c|c|c|c|c|c|c|}
\hline \multirow[b]{2}{*}{ Region } & \multicolumn{4}{|c|}{$\begin{array}{l}\text { Reed Wetland } \\
\quad\left(10^{4} \text { ha }\right)\end{array}$} & \multicolumn{4}{|c|}{$\begin{array}{l}\text { Marsh wetland } \\
\left(10^{4} \text { ha }\right)\end{array}$} \\
\hline & $\begin{array}{c}\text { Initial } \\
\text { Planned } \\
\text { Scheme }\end{array}$ & $\begin{array}{l}\text { Low } \\
\text { Flow } \\
\text { Year }\end{array}$ & $\begin{array}{c}\text { Normal } \\
\text { Flow } \\
\text { Year }\end{array}$ & $\begin{array}{l}\text { High } \\
\text { Flow } \\
\text { Year }\end{array}$ & $\begin{array}{c}\text { Initial } \\
\text { Planned } \\
\text { Scheme }\end{array}$ & $\begin{array}{l}\text { Low } \\
\text { Flow } \\
\text { Year }\end{array}$ & $\begin{array}{c}\text { Normal } \\
\text { Flow } \\
\text { Year }\end{array}$ & $\begin{array}{l}\text { High } \\
\text { Flow } \\
\text { Year }\end{array}$ \\
\hline 1 & 0.41 & $0.19-0.29$ & $0.41-0.42$ & $0.41-0.42$ & 0.31 & $0.29-0.28$ & $0.39-0.37$ & $0.38-0.37$ \\
\hline 2 & 0.91 & $0.34-0.43$ & $0.9-1.04$ & $1.15-1.14$ & 0.13 & $0.07-0.07$ & $0.15-0.15$ & $0.16-0.15$ \\
\hline 3 & 0.15 & $0.07-0.15$ & $0.2-0.19$ & $0.2-0.19$ & 0.28 & $0.11-0.17$ & $0.35-0.34$ & $0.35-0.34$ \\
\hline 4 & 0.02 & $0-0$ & $0.02-0.02$ & $0.02-0.02$ & 0 & 0-0 & 0-0 & 0-0 \\
\hline 5 & 0 & $0-0$ & $0-0$ & $0-0$ & 0.19 & $0.11-0.11$ & $0.19-0.2$ & $0.21-0.22$ \\
\hline 6 & 0.13 & $0.13-0.13$ & $0.13-0.13$ & $0.15-0.16$ & 0.51 & $0.12-0.22$ & $0.53-0.54$ & $0.64-0.61$ \\
\hline 7 & 0.16 & $0-0.16$ & $0.16-0.17$ & $0.17-0.19$ & 0.01 & $0-0$ & $0.02-0.02$ & $0.02-0.02$ \\
\hline 8 & 0.1 & $0-0$ & $0.1-0.12$ & $0.13-0.12$ & 0.2 & $0.02-0$ & $0.21-0.24$ & $0.25-0.24$ \\
\hline 9 & 0.27 & $0-0$ & $0.27-0.27$ & $0.35-0.33$ & 0.34 & $0-0$ & $0.36-0.41$ & $0.43-0.41$ \\
\hline 10 & 0.07 & $0-0$ & $0.07-0.09$ & $0.1-0.09$ & 0.25 & $0-0$ & $0.25-0.29$ & $0.31-0.3$ \\
\hline 11 & 0.11 & $0.07-0.1$ & $0.11-0.11$ & $0.13-0.13$ & 0.1 & $0.01-0$ & $0.11-0.12$ & $0.13-0.12$ \\
\hline 12 & 1.15 & $1.18-1.16$ & $1.14-1.16$ & $1.14-1.44$ & 3.41 & $0.87-1.63$ & $3.44-3.69$ & $4.25-4.1$ \\
\hline 13 & 0.07 & $0.01-0.04$ & $0.07-0.07$ & $0.09-0.09$ & 0.04 & 0-0 & $0.04-0.04$ & $0.05-0.04$ \\
\hline 14 & 0.14 & $0-0.03$ & $0.14-0.14$ & $0.19-0.18$ & 0.31 & $0.07-0.07$ & $0.31-0.35$ & $0.39-0.37$ \\
\hline 15 & 0.04 & $0-0$ & $0.04-0.05$ & $0.06-0.05$ & 0 & $0-0$ & $0-0$ & $0-0$ \\
\hline Total & 3.72 & $1.99-2.5$ & $3.77-4$ & $4.28-4.56$ & 6.07 & $1.68-2.53$ & $6.36-6.77$ & $7.57-7.3$ \\
\hline
\end{tabular}




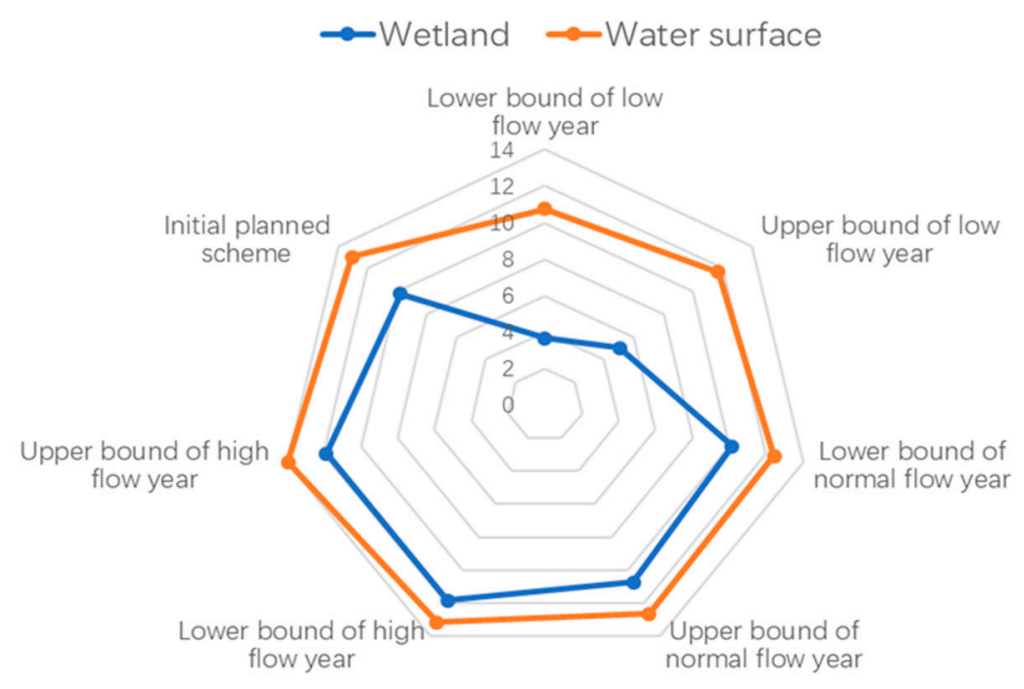

Figure 3. Restored area of wetland and water surface in different scenarios.

The total restored water surface areas of the lakes and ponds in the three scenarios were $(10.73-11.71) \times 10^{4},(12.44-12.65) \times 10^{4}$, and $(13.16-13.95) \times 10^{4}$ ha, respectively, which were changed from the initially planned schemes of $-17.69 \%$ to $-10.18 \%,-4.6 \%$ to $-2.97 \%$, and $0.92 \%$ to $7.01 \%$, respectively. The total restored water surface area of the normal flow year and the high flow year increased by $8.03-15.9 \%$ and $19.14-22.61 \%$, respectively, compared with the low flow year. The proportions of the restored fishpond area in the three scenarios, which were changed from the initially planned scheme, were $-34.93 \%$ to $-7.58 \%, 0.43 \%$ to $1.37 \%$, and $6.84 \%$ to $15.24 \%$, respectively. The proportions of the restored crab pond area in the three scenarios, which were changed from the initially planned scheme, were $-7.76 \%$ to $1.31 \%, 2.51 \%$ to $7.46 \%$, and $10.86 \%$ to $14.83 \%$, respectively.

The total restored wetland area of the lakes and ponds in the three scenarios was (3.66-5.04) $\times 10^{4}$, $(10.13-10.76) \times 10^{4}$, and $(11.86-11.87) \times 10^{4}$ ha, respectively. The proportions of the restored reed wetland in the three scenarios, which changed from the initially planned scheme, were $-46.65 \%$ to $-32.76 \%, 1.38 \%$ to $7.35 \%$, and $15.11 \%$ to $22.62 \%$, and the proportions of the restored marsh wetland were $-72.35 \%$ to $-58.26 \%, 4.73 \%$ to $11.49 \%$, and $24.77 \%$ to $20.31 \%$, respectively.

\subsection{Results of the Optimization of Water Diversion and Supplement Based on the IFDCP}

The change in the trend of the water diversion and supplement of ponds and wetlands was found to be consistent with the restored area. The supplement amount of water in the three water scenarios of the ponds was $(60,670.88-66,711.09) \times 10^{4} \mathrm{~m}^{3},(71,826.3-73,272.61) \times 10^{4} \mathrm{~m}^{3}$, and $(76,079.75-80,975.43) \times 10^{4} \mathrm{~m}^{3}$, and that of the wetlands was $(21,491.21-29,313.96) \times 10^{4} \mathrm{~m}^{3}$, $(55,811.77-59,625.65) \times 10^{4} \mathrm{~m}^{3}$, and $(65,096.17-66,138.84) \times 10^{4} \mathrm{~m}^{3}$, respectively.

The diversion and supplement of water were divided into local water resources, normal supplement, and flood resources. The water supplement amount in each scenario is shown in Figure 4 . The change rates of the supplement amount of the total local water resources, as compared to the initially planned scheme in the three scenarios, were $-8.68 \%$ to $1.08 \%,-3.35 \%$ to $1.98 \%$, and $-3.39 \%$ to $1.92 \%$, respectively. The change rates of the normal supplement amount, as compared with the initially planned scheme in the three scenarios, were $-0.77 \%$ to $4.96 \%,-0.15 \%$ to $5.02 \%$, and $-0.16 \%$ to $3.12 \%$, respectively. The change rates of the supplement amount of flood resources, as compared with the initially planned scheme in the three scenarios, were $-51.79 \%$ to $-40.53 \%, 1.02 \%$ to $3.68 \%$, and $17.57 \%$ to $21.36 \%$, respectively. 


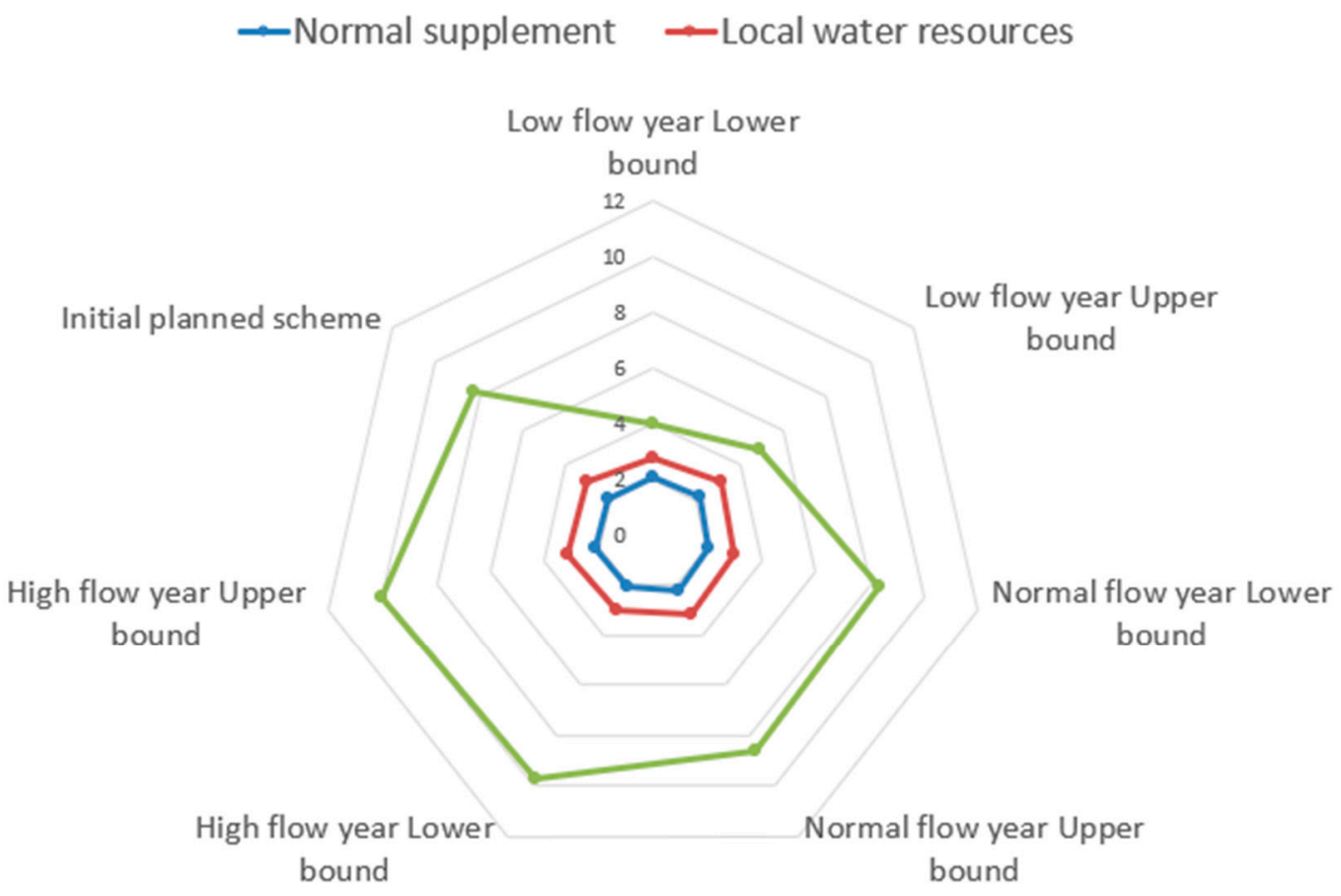

Figure 4. The water supplement amount in each scenario.

The distribution ratio of the local resources, normal supplement, and flood resources of the initially planned scheme was $22.83 \%, 15.54 \%$, and 61.63 , respectively. The proportions of the local resources, normal supplement, and flood resources were analyzed considering the IFDCP model in the three scenarios. The proportions in the low flow year were $31.6-30.35 \%, 23.37-21.45 \%$, and $45.03-48.2 \%$, respectively; in the normal flow year were $22.11-22.5 \%, 15.54-15.77 \%$, and $62.36-61.74 \%$, respectively; and in the high flow year were $20.05-20.4 \%, 14.1-14.05 \%$, and $65.85-65.56 \%$, respectively.

\subsection{Results of the Optimization of the Ecological Service Value Based on the IFDCP}

The ecological service values based on the IFDCP in the low flow year, normal flow year, and high flow year were $(7545.65-10,510.97) \times 10^{6},(14,885.19-16,401.01) \times 10^{6}$, and $(16,803.28-18,183.51) \times 10^{6} \mathrm{CNY}$, respectively, which were changed $-45.32 \%$ to $23.83 \%, 7.86 \%$ to $18.85 \%$, and $21.76 \%$ to $31.76 \%$ as compared with the initially planned scheme of $13,799.98 \times 10^{6}$ CNY. The ecological service values of different functional areas in the three scenarios are shown in Table 3. The proportions of the ecological service value of the fish pond in the three scenarios were $37.73-39.29 \%, 29.52-27.62 \%$, and $27.82-28.32 \%$; those of the crab pond were $19.11-15.33 \%, 10.76-10.42 \%$, and $10.31-10.04 \%$; those of the reed wetland were $24.2-22.83 \%, 23.31-23.36 \%$, and $23.44-24.07 \%$; and those of the marsh wetland were $18.97-22.55 \%, 36.41-38.6 \%$, and $38.43-37.57 \%$, respectively.

Table 3. Interval value of the ecological service values of different functional areas.

\begin{tabular}{|c|c|c|c|}
\hline Functional Area & $\begin{array}{l}\text { Ecological Services } \\
\text { Value of Low Flow Year } \\
\left(10^{6} \mathrm{CNY}\right)\end{array}$ & $\begin{array}{c}\text { Ecological Services Value } \\
\text { of Normal Flow Year } \\
\left(10^{6} \mathrm{CNY}\right)\end{array}$ & $\begin{array}{l}\text { Ecological Services } \\
\text { Value of High Flow Year } \\
\left(10^{6} \mathrm{CNY}\right)\end{array}$ \\
\hline Fishpond & $4129.5-2846.84$ & $4529.46-4393.53$ & $5149.19-4673.85$ \\
\hline Crab pond & $1611.27-1441.83$ & $1709.07-1602.3$ & $1826.34-1732.89$ \\
\hline Reed wetland & $2399.61-1825.86$ & $3831.08-3469.49$ & $4375.96-3939.36$ \\
\hline Marsh wetland & $2370.58-1431.11$ & $6331.4-5419.87$ & $6832.02-6457.17$ \\
\hline
\end{tabular}


A total of 12 types of ecological services-namely, food production, raw material production, water supply, carbon sequestration, atmosphere regulation, water regulation and storage, microclimate adjustment, pollution degradation, biodiversity protection, scientific culture, tourism development, and landscape aesthetics—-were analyzed in this paper. The comparison of different ecological services in the three scenarios is shown in Figure 5. Fifteen specific ecological services are reflected in the thermal diagram, including fish, crab, reed, water supply, carbon sequestration, oxygen release, water storage and regulation, microclimatic modification, plant fixation, assimilative capacity, biodiversity, scientific culture, tourism development, urban landscape, and nature landscape. In the heat map, the larger the ecological services value, the darker the color. The order of the main ecological services in the low flow year was as follows: food production (27.27-25.53\%) > pollution degradation (20.83-20.7\%) > microclimate adjustment (13.45-13.47\%) > water supply (11.48-11.07\%) > water regulation and storage (10.26-11.22\%); the order in the normal flow year was as follows: pollution degradation (29.2-28.35\%) $>$ food production (19.04-17.75\%) > microclimate adjustment (18.4-17.92\%) > water regulation and storage (9.14-10.36\%) > water supply (8.24-7.72\%); and the order in the high flow year was as follows: pollution degradation (30.27-28.19\%) > microclimate adjustment $(19.03-17.83 \%)>$ food production $(18.04-17.86 \%)>$ water regulation and storage $(8.97-10.39 \%)>$ water supply $(7.8-7.8 \%)$.

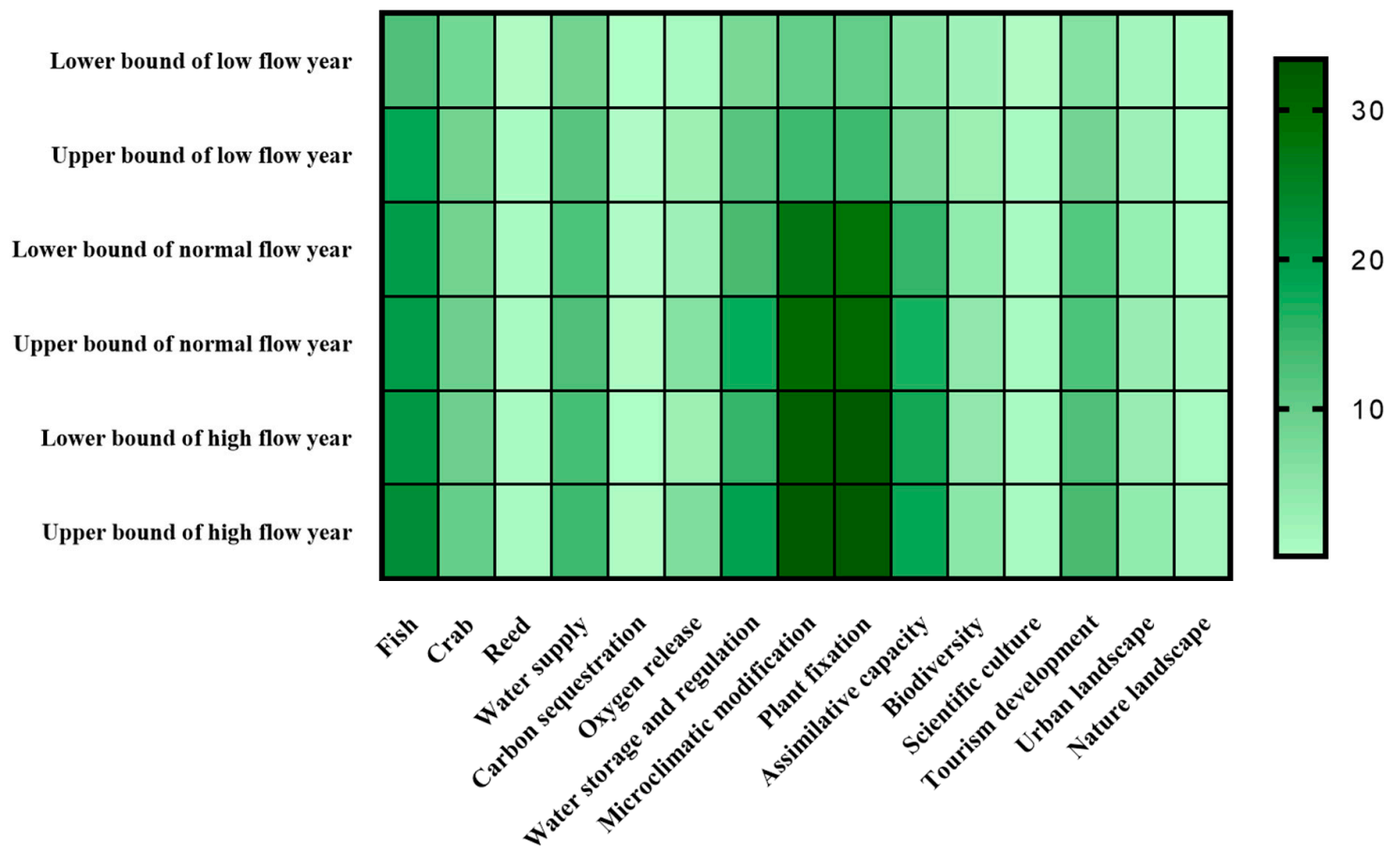

Figure 5. The comparison of different ecological services.

\subsection{Comparison Results of the IDCP and IFDCP}

This paper aimed to maximize the ecological service value of the western Jilin Province by optimizing the diversion and supplement of water. First, the IDCP was used for optimization, and then the fuzzy programming method was performed based on the IDCP model. The IDCP and IFDCP models from the perspective of the total water surface area, and the total ecological service value optimizations were compared (Figures 6 and 7). For the convenience of analysis, the IDCP and IFDCP model were called Model 1 and Model 2, respectively. 


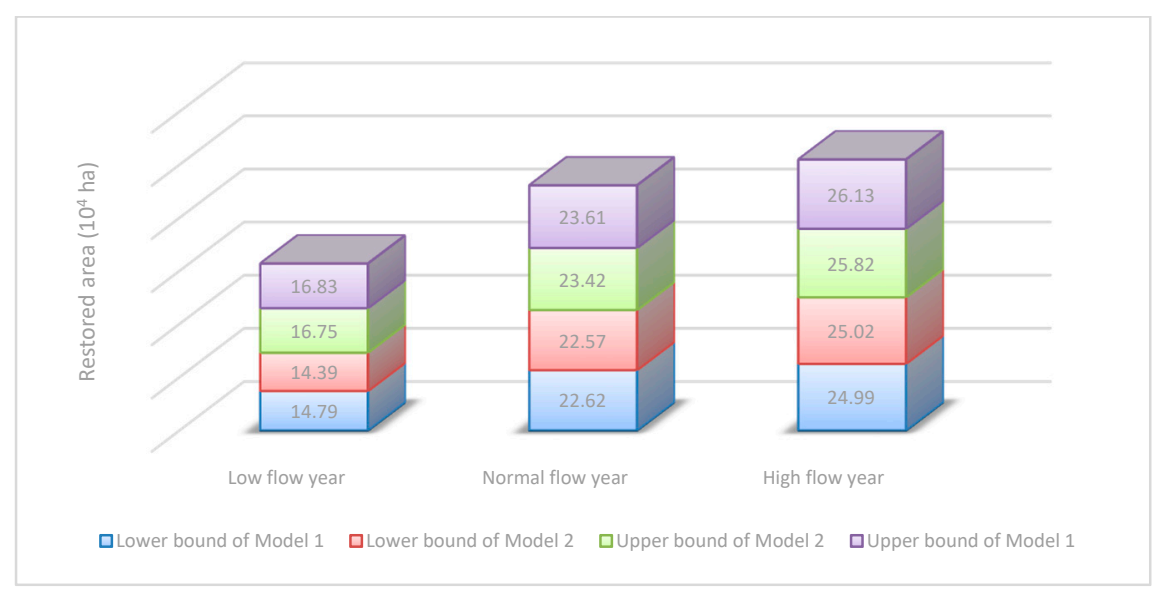

Figure 6. The comparison of the interval, double-sided, chance-constrained stochastic programming (IDCP) and IFDCP models from the perspective of the total water surface area.

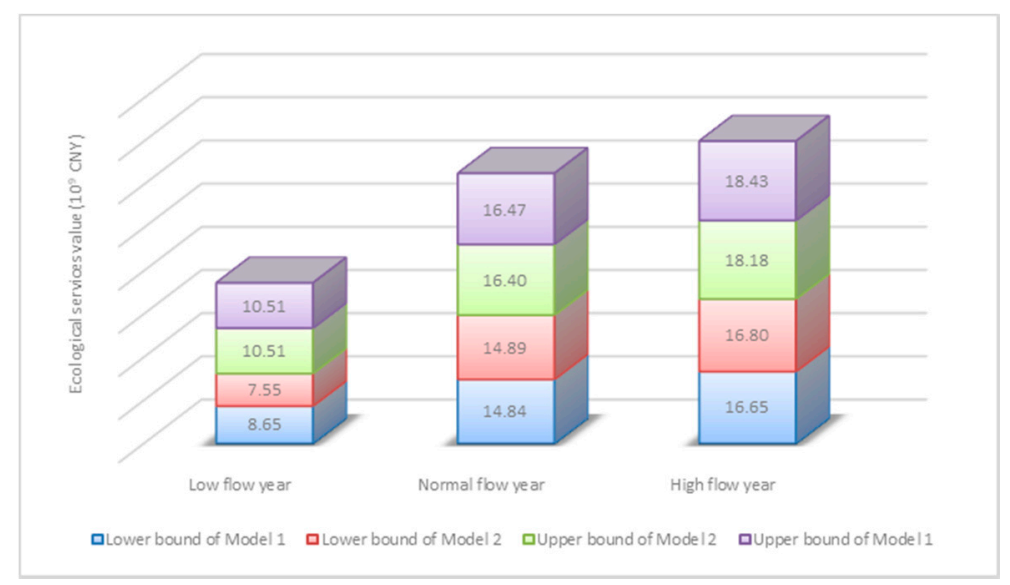

Figure 7. The comparison of the IDCP and IFDCP models from the perspective of the total ecological service value.

Compared to Model 1, the values of interval range of the total area of ponds in Model 2 in the low flow year, normal flow year, and high flow year increased by $15.18 \%,-14.66 \%$, and $-29.49 \%$, respectively, and that of the total ecological service value was increased by $59.39 \%,-7.46 \%$, and $-22.29 \%$, respectively.

\subsection{Comparison Results of Multiple Models Based on the Optimization of the Ecological Service Value}

Considering the ecological service value and the restored functional area of region 1 (Nongan County, $i=1-7$ ) in the normal flow year as examples, the IFDCP model (Model 2) developed in this paper was compared with the fuzzy, double-sided, chance-constrained programming model (Model 3); the fuzzy, two-stage, double-sided, chance-constrained programming model (Model 4); and the fuzzy, two-stage, double-sided, chance-constrained programming optimization model (Model 5). The restored area and the ecological service values of each model are shown in Tables 4 and 5. 
Table 4. Comparison of the restored functional area of region 1, optimized by different models.

\begin{tabular}{|c|c|c|c|c|c|c|c|c|c|c|c|c|}
\hline \multirow{2}{*}{$\begin{array}{l}\text { Lake } \\
\text { and } \\
\text { Pond }\end{array}$} & \multicolumn{3}{|c|}{$\begin{array}{l}\text { Fishpond Area } \\
\qquad\left(10^{4} \mathrm{ha}\right)\end{array}$} & \multicolumn{3}{|c|}{$\begin{array}{l}\text { Crab Pond Area } \\
\left(10^{4} \mathrm{ha}\right)\end{array}$} & \multicolumn{3}{|c|}{$\begin{array}{l}\text { Reed Wetland Area } \\
\qquad\left(10^{4} \mathrm{ha}\right)\end{array}$} & \multicolumn{3}{|c|}{$\begin{array}{l}\text { Marsh Wetland Area } \\
\qquad\left(10^{4} \mathrm{ha}\right)\end{array}$} \\
\hline & $\begin{array}{c}\text { Model } \\
2\end{array}$ & $\begin{array}{c}\text { Model } \\
3\end{array}$ & $\begin{array}{l}\text { Model } \\
5\end{array}$ & $\begin{array}{l}\text { Model } \\
2\end{array}$ & $\begin{array}{l}\text { Model } \\
3\end{array}$ & $\begin{array}{l}\text { Model } \\
5\end{array}$ & $\begin{array}{c}\text { Model } \\
2\end{array}$ & $\begin{array}{l}\text { Model } \\
3\end{array}$ & $\begin{array}{l}\text { Model } \\
5\end{array}$ & $\begin{array}{c}\text { Model } \\
2\end{array}$ & $\begin{array}{l}\text { Model } \\
3\end{array}$ & $\begin{array}{c}\text { Model } \\
5\end{array}$ \\
\hline$i=1$ & $0.04-0.03$ & 0.04 & 0.02 & $0-0$ & 0 & 0 & $0.08-0.08$ & 0.08 & 0.09 & $0.03-0.03$ & 0.03 & 0.02 \\
\hline$i=2$ & $0.72-0.74$ & 0.66 & 0.86 & $0-0$ & 0 & 0 & $0.27-0.27$ & 0.27 & 0.35 & $0.17-0.16$ & 0.17 & 0.18 \\
\hline$i=3$ & $0-0$ & 0 & 0 & $0.01-0.01$ & 0.01 & 0.01 & $0-0$ & 0 & 0 & $0-0$ & 0 & 0 \\
\hline$i=4$ & $0-0$ & 0 & 0 & $0-0$ & 0 & 0 & $0-0$ & 0 & 0 & $0-0$ & 0 & 0 \\
\hline$i=5$ & $0-0$ & 0 & 0 & $0.07-0.09$ & 0.10 & 0.08 & $0.03-0.03$ & 0.03 & 0.02 & $0.08-0.08$ & 0.08 & 0.09 \\
\hline$i=6$ & $0-0$ & 0 & 0 & $0-0$ & 0 & 0 & $0.01-0.01$ & 0.01 & 0.01 & $0.04-0.04$ & 0.04 & 0.04 \\
\hline$i=7$ & $0-0$ & 0 & 0 & $0.2-0.26$ & 0.25 & 0.23 & $0.03-0.03$ & 0.03 & 0.02 & $0.06-0.06$ & 0.06 & 0.07 \\
\hline Total & $0.76-0.77$ & 0.69 & 0.88 & $0.28-0.36$ & 0.36 & 0.33 & $0.42-0.42$ & 0.42 & 0.49 & $0.38-0.37$ & 0.38 & 0.39 \\
\hline
\end{tabular}

Table 5. Comparison of the ecological service value optimized by different models.

\begin{tabular}{|c|c|c|c|c|}
\hline Evaluation Indices & $\begin{array}{c}\text { Ecological } \\
\text { Services Value of } \\
\text { Model } 2 \\
\left(10^{6} \mathrm{CNY}\right)\end{array}$ & $\begin{array}{c}\text { Ecological } \\
\text { Services Value of } \\
\text { Model } 3 \\
\left(10^{6} \mathrm{CNY}\right)\end{array}$ & $\begin{array}{c}\text { Ecological } \\
\text { Services Value of } \\
\text { Model } 4 \\
\left(10^{6} \mathrm{CNY}\right)\end{array}$ & $\begin{array}{c}\text { Ecological } \\
\text { Services Value of } \\
\text { Model } 5 \\
\left(10^{6} \mathrm{CNY}\right)\end{array}$ \\
\hline Fish & $1958.27-1989.00$ & 1807.94 & 1956.00 & 1793.53 \\
\hline Crab & $876.45-922.63$ & 869.76 & 856.80 & 658.7 \\
\hline Reed & $65.09-74.92$ & 73.95 & 67.00 & 76.52 \\
\hline Water supply & $1227.15-1265.85$ & 1156.58 & 1515.98 & 1300.64 \\
\hline Carbon sequestration & $25.90-37.35$ & 28.95 & 26.12 & 30.62 \\
\hline Oxygen release & $253.37-589.29$ & 283.30 & 255.63 & 299.87 \\
\hline Water storage and regulation & $1360.19-1699.62$ & 1366.55 & 1546.01 & 1524.10 \\
\hline Microclimatic modification & 2738.47-2938.84 & 2961.60 & 2683.25 & 3268.59 \\
\hline Plant fixation & $2833.90-3027.17$ & 3067.41 & 2747.03 & 3383.72 \\
\hline Assimilative capacity & $1511.92-1622.56$ & 1640.33 & 1469.00 & 1809.48 \\
\hline Biodiversity & $403.16-437.04$ & 407.25 & 445.26 & 453.40 \\
\hline Scientific culture & $76.27-97.12$ & 78.32 & 85.63 & 87.19 \\
\hline Tourism development & $1136.33-1214.01$ & 1159.09 & 1267.29 & 1290.46 \\
\hline Urban landscape & $309.77-339.92$ & 313.27 & 342.51 & 348.77 \\
\hline Nature landscape & $108.96-145.68$ & 125.31 & 137.00 & 139.51 \\
\hline Total & $14,885.19-16401.01$ & $15,339.59$ & $15,400.51$ & $16,465.10$ \\
\hline
\end{tabular}

\section{Discussion}

\subsection{Analysis of the Restored Area of Wetlands, Lakes, and Ponds Based on the IFDCP}

In the high flow year, the restored water surface area of lakes and ponds was higher than the initially planned scheme with enough floodwater amount. In the normal flow year, the water area met the minimum constraints, but did not reach the initial plan because the water amount was limited. In the low flow year, some regions had to lower the limit of the water surface area in order to meet the allocation of short water resources. The total area of the fishpond in the normal flow year and the high flow year was higher than the initial plan in both the years. In the low flow year, the restored fishpond area of regions 5, 6, 11, and 13 was not less than the initial scheme. The fish pond area of regions 8 and 10 was significantly lower than the initial scheme because these two regions had higher water requirements, whereas the local water resources and normal supplement were relatively low, and the flood resources were significantly lower than the normal flow year and the high flow year. The restored area trends of different scenarios of crab ponds were found to be similar to the fishponds. However, in the low flow year, the difference between the restore crab area in different regions and the initial scheme was small, which meant that the water resources could basically meet the water requirement of the crab pond.

The restored wetland area significantly improved in the normal flow year and high flow year as compared to the low flow year. As the objective of the model was to obtain the highest ecological service value, the wetland that can generate higher ecological services should be supplemented after 
meeting the requirements of the ponds. Li et al. studied the wetlands in the middle and lower reaches of the Yangtze River, which showed the irreplaceable importance of wetlands [16]. The restored area of reed and marsh wetlands in the normal flow year and the high flow year was higher than the initial scheme, and the restored area of the marsh wetland was relatively higher than that of the reed wetland. However, the results of the low flow year showed completely opposite results - that the restored marsh wetland area decreased significantly. At the same time, only the restored reed wetland area in region 12 was higher than the initial scheme. Water supplement prioritizes the water use of reed wetlands and ponds, and finally the marsh wetland that can produce relatively the highest ecological service value. Therefore, when there is enough water, the restored marsh wetland area will be improved, in order to increase the ecological service value, whereas water cannot be supplemented to the marsh wetland in the situation of water shortage. In the case of the low flow year, the lower bound of the restored marsh wetland area was found to be higher than the upper bound. It was speculated that the constraints of the area were at the lower limit, while there was more water in the high flow year; consequently, more water was supplemented to the marsh wetland.

\subsection{Analysis of the Optimization of Water Diversion and Supplement Based on the IFDCP}

On the whole, the local water resources basically remained unchanged as the amount of flood resources increased, which indicates that the local water resources are used preferentially. The normal supplement could be realized in six regions. The upper and lower bounds of the normal supplement in most of the regions in the three scenarios were basically the same. Among them, the upper bound of the normal supplement in the high flow year of regions 6 and 8 decreased by $100 \%$ and $71.51 \%$, respectively, compared with the initial scheme, which indicates that the normal supplement amount will be reduced when the water is sufficient. The upper and lower bounds of the flood resource supplement were found to be lower than the initial scheme in the low flow year, because the flood amount was too small, which was opposite in the high flow year due to the sufficient flood resources. Flood resources were considered as the main form of water supplement in different scenarios. Floods are generated naturally, and often offer significant ecological benefits, such as the deposition of rich and fertile sediments on the land near the river and the supplement of groundwater [17]. The proportion of the use of flood resources gradually increased as the amount of flood increased, whereas that of local resources and normal supplements showed a downward trend. The increase in flood utilization in the normal flow year and the high flow year indicates that the western Jilin Province is short of water resources and cannot meet the water requirement of all functions. Therefore, the effective use of flood for water supplement shows a positive significance for enhancing the ecological service value.

\subsection{Analysis of the Optimization of the Ecological Service Value Based on the IFDCP}

The ecological service value could not meet the planning requirements in the low flow year, whereas that of the normal flow year and high flow year significantly improved after optimization. The proportion of the ecological service value of ponds decreased, whereas that of wetlands, especially marsh wetlands, significantly increased with an increase in the flood resources amount, which further indicates that the main reason for the improvement in the ecological service value was the increased wetland area when water was sufficient. The marsh wetland requires less water than the reed wetland when the area is the same, so water is supplemented to the marsh wetland after meeting the requirement of other areas. Therefore, more change was observed in the ecological service value of the marsh wetland. In one of the cases, the lower bound of the functional areas of the proportion of the ecological service value was found to be higher than the upper bound in some regions. However, this is normal due to differences in parameters.

Food production and pollution degradation contributed nearly half of the ecological services in the low flow year. Food production is produced in ponds, including fish and crab. The service of pollution degradation is produced in wetlands, including plant fixation and assimilative capacity. The proportion of the ecological service value generated by wetlands increased in the normal flow 
year and the high flow year. Among them, pollution degradation, microclimate adjustment, and food production produced more ecological services. Previous study has proved that the wetland can regulate the surface runoff and purify the water quality, and its function of recharging groundwater is particularly important in arid and the semi-arid areas [18]. In the high flow year, the ecological services generated by wetlands were at nearly half. The wetlands primarily improved the ecological service value by plant fixation, assimilative capacity, and microclimate adjustment when water is sufficient.

\subsection{Comparison Analysis of the IDCP and IFDCP}

Some regions (represented by regions $4,8,9,10$, and 15) were found in a stage of water shortage in the low flow year, and the optimization range was small. The change in the trend of upper and lower bounds was the same after the fuzzy method was added, resulting in the interval range of Model 2 being greater than that of Model 1. Adding a fuzzy method will fully consider the fuzzy uncertainty of the minimum value of the water surface area, the functional area, and the total area when water resources can guarantee the basic water requirement. Then the lower and upper bounds of Model 1 were increased and reduced, respectively [19].

\subsection{Comparison Analysis of Multiple Models Based on the Optimization of the Ecological Service Value}

The optimization results of the restored functional area of Model 3 were found within the range of the interval results of Model 2. The optimization results of the total functional area (except crab ponds) of Model 5 were found to be higher than the upper bounds of Model 2 (Table 4). The optimization results of the most evaluation indicators of Models 3-5 were found within the interval results of Model 2 (Table 5). The total ecological service values of Models 3 and 4 were found in the range of the interval results of Model 2. The total ecological service value of Model 5 was found to be $0.39 \%$ higher than the upper bound of Model 2. Model 5 was optimized based on Model 4. As compared to Model 4, the ecological service (such as fish, crabs, and water supply) value produced by fish and crab ponds of Model 5 was reduced, whereas the ecological service (such as microclimate adjustment, plant fixation, and assimilative capacity) value produced by reed and marsh wetlands was increased. This indicates that Model 5 achieved higher ecological service value by decreasing the water surface area limit. However, Models 3-5 did not fully consider the volatility of the parameters except precipitation, water surface area, and flood resources, and cannot provide a flexible planning solution. In addition, Models 4 and 5 set the probability distribution of the flood inflow scenario, which was impacted by subjective factors and was uncertain for the model. Model 5 decreased the water surface area limit in order to obtain the maximum ecological service value, but it was difficult to apply to the actual situation. In the process of adjusting the water diversion and the supplement plan in the western region of Jilin Province, it is necessary to allocate water resources reasonably within a certain range, according to different situations. In summary, the IFDCP model developed in this paper demonstrates certain feasibility, and at the same time, it is convenient and more flexible to distribute and supplement water resources in the western part of Jilin Province.

\section{Conclusions}

In this paper, the IFDCP model was developed to achieve the maximum value of ecological services by optimizing the water diversion and supplement of the western region of Jilin Province. The IFDCP model optimization results showed that when there is enough water, the restored marsh wetland area will be improved to increase the ecological service value, and the effective use of flood for water supplement has a positive significance for enhancing the ecological service value. The optimization results of most evaluation indicators of previous models were found within the interval results of the IFDCP model. However, the previous models did not fully consider the volatility of parameters and cannot provide a flexible solution, and there was uncertainty to the models that is difficult to be applied to the actual situation. The optimized range of total ecological service value can be increased by nearly $10 \%$ in an IFDCP model compared with the previous models. In the normal flow year, 
the decision-making space of the crab pond area increased by nearly $25 \%$ compared with previous models, and that of the marsh wetland increased by nearly $3 \%$, which facilitates the flexible planning of relevant functional areas. In conclusion, the IFDCP model was more flexible and practical as compared to the models that were developed previously, which provides a feasible plan for water diversion and supplement.

Author Contributions: Conceptualization, L.Y. and W.C.; methodology, W.C.; software, C.M.; validation, C.M., L.Y. and W.C.; formal analysis, B.C.; investigation, L.Y.; resources, W.C.; data curation, B.C.; writing-original draft preparation, M.L.; writing—review and editing, L.Y.; visualization, C.M.; supervision, M.L. All authors have read and agreed to the published version of the manuscript.

Funding: This research received no external funding.

Acknowledgments: The paper was edited by Sagesci Language Editing Services.

Conflicts of Interest: The authors declare no conflict of interest.

\section{References}

1. Zhang, L.; Hou, G.L.; Zhang, G.X.; Liu, Z.L.; Sun, G.Z.; Li, M.N. Calculation of Wetlands Ecological Water Requirement in China's Western Jilin Province Based on Regionalization and Gradation Techniques. Appl. Ecol. Environ. Res. 2015, 14, 463-478. [CrossRef]

2. Zhang, J.Z.; Yu, Z.Q.; Yu, T.F.; Si, J.H.; Feng, Q.; Cao, S.X. Transforming flash floods into resources in arid China. Land Use Policy 2018, 76, 746-753. [CrossRef]

3. Hao, C.L.; Yan, D.H.; Qin, T.L.; Zhang, C.; Yin, J. Water Ecosystem Services and Their Value-a Case Study in Luan River Basin, North China. Appl. Mech. Mater. 2014, 448, 225-234. [CrossRef]

4. Zedler, J.B.; Kercher, S. Wetland resources: Status, trends, ecosystem services, and restorability. Annu. Rev. Environ. Resour. 2005, 30, 39-74. [CrossRef]

5. Li, T.; Gao, X. Ecosystem Services Valuation of Lakeside Wetland Park beside Chaohu Lake in China. Water 2016, 8, 301. [CrossRef]

6. Wu, G.; Tan, L.B.; Yan, Y.; Tian, Y.; Shen, Y.; Cao, H.M.; Dong, M.T. Measures and planning for wetland restoration of Xianghe Segment of China's Grand Canal. Int. J. Sust. Dev. World Ecol. 2016, 23, 326-332. [CrossRef]

7. Zhang, L.; Wang, M.H.; Hu, J.; Ho, Y.S. A review of published wetland research, 1991-2008: Ecological engineering and ecosystem restoration. Ecol. Eng. 2010, 36, 973-980. [CrossRef]

8. Zhang, L.; Hou, G.L.; Li, F.P. Dynamics of landscape pattern and connectivity of wetlands in western Jilin Province, China. Environ. Dev. Sustain. 2020, 22, 2517-2528. [CrossRef]

9. Cai, B.F.; Wang, X.E.; Li, Y. Application of a Double-Sided Chance-Constrained Integer Linear Program for Optimization of the Incremental Value of Ecosystem Services in Jilin Province, China. Water 2017, 9, 629. [CrossRef]

10. Cai, B.F. Research on the Optimization Model of Ecosystem Service Value of River-lake Connectivity Project in Western Jilin Province. Ph.D. Thesis, Jilin University, Changchun, China, 2019.

11. Cai, B.F.; Meng, C.; Wang, X.E.; Li, Y. Application of a Fuzzy Two-Stage Chance Constrained Stochastic Programming Model for Optimization of the Ecological Services Value of the Interconnected River System Network Project in the Western Jilin Province, China. Water 2019, 11, 68. [CrossRef]

12. Liu, B.D.; Iwamura, K. Fuzzy programming with fuzzy decisions and fuzzy simulation-based genetic algorithm. Fuzzy Sets Syst. 2001, 122, 253-262. [CrossRef]

13. Qu, G.L.; Tan, S.K.; Zhou, M.; Lu, S.S.; Tao, Y.H.; Zhang, Z.; Zhang, L.; Yan, D.P.; Guan, X.L.; Wu, G. An interval chance-constrained fuzzy modeling approach for supporting land-use planning and eco-environment planning at a watershed level. J. Environ. Manag. 2017, 204, 651-666.

14. Zhang, C.L.; Engel, B.A.; Guo, P. An Interval-based Fuzzy Chance-constrained Irrigation Water Allocation model with double-sided fuzziness. Agric. Water Manag. 2018, 210, 22-31. [CrossRef]

15. Cheng, H.C.; Li, Y.P.; Sun, J. Interval Double-Sided Fuzzy Chance-Constrained Programming Model for Water Resources Allocation. Environ. Eng. Sci. 2018, 35, 525-544. [CrossRef] 
16. Li, X.W.; Yu, X.B.; Jiang, L.G.; Li, W.Y.; Li, W.Y.; Liu, Y.; Hou, X.Y. How important are the wetlands in the middle-lower Yangtze River region: An ecosystem service valuation approach? Ecosyst. Serv. 2014, 10, 54-60. [CrossRef]

17. Yang, W.; Zhang, L.P.; Zhang, Y.J.; Li, Z.L.; Xiao, Y.; Xia, J. Developing a comprehensive evaluation method for Interconnected River System Network assessment: A case study in Tangxun Lake group. J. Geogr. Sci. 2019, 29, 389-405. [CrossRef]

18. Uluocha, N.O.; Okeke, I.C. Implications of wetlands degradation for water resources management: Lessons from Nigeria. GeoJournal 2004, 61, 151-154. [CrossRef]

19. Sun, Z.; Wen, J.Y.; Hu, Y.; Li, Z.; Li, Y.; Pang, T.Y. Interval Fuzzy Linear Programming for Total Amount Control and Emissions Trading of Regional Atmospheric Pollutants. In Proceedings of the International Conference on Remote Sensing, Environment and Transportation Engineering, Nanjing, Jiangsu, China, 1-3 June 2012.

(C) 2020 by the authors. Licensee MDPI, Basel, Switzerland. This article is an open access article distributed under the terms and conditions of the Creative Commons Attribution (CC BY) license (http://creativecommons.org/licenses/by/4.0/). 